Изместьев Сергей Владимирович

практикующий юрист, член Ассоциации юристов стран Черноморско-Каспийского региона

\section{КРИЗИС ГОСУДАРСТВА КАК СОЦИАЛЬНО-ПОЛИТИЧЕСКОГО ИНСТИТУТА В ЭПОХУ ГЛОБАЛИЗАЦИИ}

Аннотация:

В статье рассматривается влияние процессов глобализации на государство как социально-политический институт, связанные с этим угрозы и проблемы в исторической перспективе на примере Европы. В качестве основных проблем названы возникновение сфер общественной и экономической жизни, регулирование которых невоз можно на национальном уровне; формирование единого мирового социокультурного пространства; рост транснациональной экономики; неустойчивость традиционных общественных институтов перед факторами международного воздействия. Отдельно описываются вопросы деградации государственных учреждений, их захвата транснациональными группами влияния криминализации и трансформации в фактор внутри- и внешнеполитической угрозы. Автор анализирует перспективу эволюционного "расслоения» полномочий государства между образуемыми наднациональными структурами управле ния обществом и наделенными государственными полномочиями муниципалитетами. Также выделяются два сложившихся типа глобализации, их проблемы и перспективы. Предлагаются развитие международного права, создание на его основе полномочных наднациональных структур и возвращение к модернистскому проекту развития единого общества.

Ключевые слова:

глобализация, десакрализация власти, кризис государства, криминальное государство, несостоятельное государство, захваченное государство, глобальная безопасность, наднациональная власть, сверхгосудаство, постполитическое будущеe.
Izmestyev Sergey Vladimirovich

Practicing Lawyer, Member of the Association of Lawyers of the Black Sea-Caspian Region

\section{THE CRISIS OF A STATE AS A SOCIAL AND POLITICAL INSTITUTION IN THE ERA OF GLOBALIZATION}

Summary:

The paper researches how the process of globalization affects the state as a social and political institution, and the related threats and problems in a historical perspective using the example of Europe. Among the main challenges mentioned in the paper are social and economic relations which are impossible to regulate at the national level, the global social and cultural space, the growth of the transnational economy, the instability of traditional social institutions to factors of international influence. The problem of degradation of state institutions, their capture by transnational influence groups, criminalization, and transformation into an internal and foreign policy threat factor are described in detail. The author considers the possibility of evolutional "separation" of the state authorities between building supranational society government structures and local government bodies delegated with state governmental authorities. Moreover, the author differentiates two developed types of globalization, their problems, and the prospects. The development of the international law, creation of empowered supranational structures based on the international law and the return to the modernistic concept of developing a united society is proposed.

Государство, возникшее в человеческом обществе на заре развития, несколько тысяч лет являлось важнейшим социальным институтом, основой политической системы общества, силой, организующей, направляющей и контролирующей совместную деятельность и отношения людей, общественных групп, классов, союзов. История образования государства как целостного механизма регулирования общественных отношений уходит корнями в развитие патриархальных семей, родов и в конечном счете сформированных ими народов.

На определенном этапе человеческое общество пришло к необходимости установления универсального баланса интересов личностей, сословий, конфессий в целях общего выживания и обеспечения общего блага. Механизмом балансирования интересов стала политическая власть, наделенная функциями регулирования и принуждения.

На формирование и развитие института государства повлияла территориальная раздробленность общества, что прочно привязало данный общественный институт к отдельным территориям, а также связало его с устоями, культурой, традициями и экономическим укладом конкретных народностей. Поскольку будущее ковалось в постоянной конкуренции между территориально обособленными народностями, то государство неизбежно приобрело свойства защиты 
национальных интересов от посягательств иных народов, а также право на насилие по отношению к конкурентам.

Ошибочно полагать, что развитие государства значительно способствовало развитию человеческого общества. В самом обществе присутствовали и присутствуют иные регуляторные механизмы: мораль, традиции, религия, культура. Можно сказать, что государство служило скорее инструментом выживания народов в условиях жестокой борьбы за ограниченные ресурсы и межнациональной конкуренции. Так, укрепление государственности Рима, формирование военной аристократии и диктатуры, было связано с необходимостью его обороны и захвата ресурсов у соседей.

В ходе реализации захватнической политики государства вырабатывали различный подход к составляющим их народам и территориям: коренным, союзным, завоеванным. Так появились империи, названные впоследствии лидером русской революции В. Лениным «тюрьмой народов» [1].

Все больше государство выражалось в применении насилия как во внешней политике, так и во внутренней. Право на осуществление данного насилия присваивалось кланами, группами, классами, получившими политическую власть.

Сильная централизованная государственная власть стала признаком обществ с низким уровнем самосознания, культуры и развития, для которых был характерен разрыв между интересами общества и правящего клана. Крупные государства с узурпированной политической властью и порабощенными народами не способствовали развитию в них общественных и экономических отношений, сдерживали их, что неизбежно приводило к распаду до естественных единиц - мононациональных «малых» государств, естественность существования которых обоснована в работе Л. Кора «Распад государств». Он справедливо отмечал, что «в промежуточный период между интеллектуальными ледниковыми периодами господства великих держав история, по всей вероятности, повторится, и мир, вновь малый и свободный, опять испытает те чары культурного величия, которые характеризовали миры малых государств Средневековья и Древней Греции» [2, с. 241].

Действительно, наряду с протогосударствами (самоуправляемыми общинами - «полисами») Древней Греции ярким примером этого является Европа в начале и середине Средневековья (VI-XIII вв.), когда освободившиеся от римского ига народы, фактически при отсутствии государственной власти (феодальная революция), сделали значительный рывок в экономическом, демографическом и культурном развитии - только численность населения Европы увеличилась втрое. Различные слои общества пережили небывалый подъем «вовлеченности и участия» в управление общественными делами. Об этом замечательно пишет К. Уикхем в монографиии «Средневековая Европа: от падения Рима до Реформации» [3, с. 288].

Место государства заняли общинное самоуправление, традиции и религиозная мораль. В то время когда высокоцентрализованные государства Европы - Византия, Омейядский халифат и Аль-Андалус в Испании - стали примером деградации, коррупции и постепенного упадка.

Дальнейшее укрепление института государства в Европе было вынужденным ответом на внешние политические и климатические вызовы: неурожаи, голод и эпидемию чумы после 1400 г. Возникновение здесь централизованных государств отбросило развитие гражданского общества, местного самоуправления, культуры на много столетий назад, привело к религиозным войнам, агрессии, инквизиции, массовой гибели и упадку экономик. Европе потребовалось еще 400 лет на поиск механизмов защиты личности и общества от государственного произвола, насилия и узурпаций.

Ситуация изменилась в ходе Реформации, в эпоху Просвещения посредством череды социальных потрясений - революций, когда обществом были выработаны принципы общественного контроля, разделения властей, «сдержек и противовесов», баланса между интересами личности, общества и навсегда отчужденного от них государства в лице политических и аристократических элит (теория «общественного договора»).

С этого момента начинается уменьшение значимости государства как социального института, что обусловливается следующими факторами:

- появлением механизмов общественного контроля и саморегулирования в рамках фрормирования гражданского общества;

- развитием местного самоуправления как деятельности граждан по самостоятельному решению вопросов местного значения, осуществляемому под собственную ответственность;

- фоормированием механизмов международного регулирования конфликтов;

- развитием международного права и международного правосудия;

- глубокой международной экономической интеграцией;

- расширением международного культурного и информационного обмена. 
Ярким примером «разгосударствления» стали Соединенные Штаты, где большая часть властных полномочий закрепилась на местном уровне, а некоторые - делегированы общественным институтам. По этому же пути после падения в конце XX в. железного занавеса пошли народы Европы, делегировав часть государственных полномочий надгосударственным общеевропейским и иным международным структурам (например, оборону - НАТО), а также наделив государственными полномочиями широко развитые муниципалитеты, передав часть регуляторных функций общественным институтам.

Происходившие в первой половине XX в. попытки строительства сильных централизованных государств в Европе были связаны с политической узурпацией, насилием, тоталитаризмом и международной агрессией. Такие государства, основанные на тоталитарных идеологиях и насилии, показали себя нестабильными, недолговечными и потерпели политический и экономический крах. На их территории возникли в большинстве своем мононациональные «малые» государства, включившиеся в европейскую, евразийскую и мировую экономическую и политическую интеграцию. При этом на каждом этапе такой интеграции государства утрачивали государственные признаки, добровольно делегировали часть суверенитета международным структурам.

Основными фракторами ослабления государства как социального института в начале XXI в. стала культурная и экономическая глобализация.

Так, в начале нашего столетия с развитием Всемирной информационно-телекоммуникационной сети Интернет, технологий мобильного доступа и ускоренной цифровизацией всех отраслей жизни общества начало формироваться единое глобальное социокультурное пространство, базирующееся на принципах интернационализма, антропоцентризма, плюрализма и толерантности, с огромной скоростью затягивающее в свой ареал молодые поколения жителей различных государств. При таком подходе размываются традиционные понятия национальных интересов, исчезают культурные различия, а глобализованная экономика уравнивает экономические интересы людей.

Большим шагом станет внедрение технологии нейрокомпьютерных интерфейсов для связи мозга человека с глобальной беспроводной сетью, которые сейчас активно разрабатываются. Какими государственными интересами будет руководствоваться такой «глобализованный», подключенный к единой сети человек?

Регулирование международных политических и экономических споров все больше делегируется отдельными государствами и их союзами международным ассамблеям и арбитрам. Появилась практика распространения ведущими странами и их объединениями норм своего законодательства на регулирование правоотношений за пределами их территорий, например всемирное признание патентов отдельных стран (США, членов ЕС) на международном уровне. Активно развивается транснациональное торговое право.

Резко снижается роль национального права, которое либо унифицируется с международными нормами, либо делегирует регулирование вопросов международным структурам. Яркий пример тому - действующая Конституция России, закрепляющая приоритет международного права.

Глобализованная финансовая система столкнулась с вызовом появления криптовалют, эмитируемых негосударственными структурами, разрушающими исконную монополию государств на денежную эмиссию. Широко распространяется практика использования корпорациями частных военных компаний (армий) для решения экономических вопросов силовыми средствами. Потенциал таких «войск» зачастую превосходит возможности вооруженных сил отдельных стран.

При сохранении таких тенденций формирование единой культуры, идеологии, права, правосудия, возможно электронного, и человеческой морали - вопрос ближайшего будущего. Наступает эпоха «глобального человечества» без барьеров, наций и границ. Географические и культурные границы «размываются», формируются транснациональные общности людей, подобные тем, что были в раннем Средневековье, основанные на общих целях, экономических и культурных ценностях.

Будет ли в этом новом глобальном мире место такому социальному институту, как государство? Каков его генезис?

По сути, государство носит территориальный и национальный характер, направлено на защиту или продвижение территориальных и национальных интересов. В новой глобальной среде эти понятия постепенно размываются, как и категория самой личности, какой мы ее знаем. В частности, в большинстве развитых стран сегодня человек свободен в определении своей национальности, половой принадлежности. Не кажется невероятной и ситуация, когда выбор гражданства станет таким же легким и свободным, будет осуществляться в заявительном порядке по сети Интернет, а государства смогут привлекать себе граждан, как акционеров на бирже, 
например, в обмен на инвестиции. Уже сегодня рядом государств успешно применяется практика подобной «продажи» гражданства (инвестиционных паспортов).

Директор Центра культурного консерватизма при исследовательском институте Free Congress Foundation У. Линд заявляет: «Глобализация - сила, которая буквально разрушает значение и суть государства. Это, в свою очередь, ускоряет распад государства. Например, правительства индустриально развитых государств заявляют своим гражданам, что причиной безработицы является аутсорсинг - рабочие места экспортируются за рубеж и власти никак не могут с этим бороться. В результате в глазах граждан государство теряет свое значение. Государство становится институтом, который не достоин их лояльности» [4].

Последовательная тенденция ослабления государств, их отказа от экономического и социального патернализма, неспособность противостоять глобальным вызовам раздражают людей, вынуждают искать защиты и справедливости у международных организаций и институтов: в международных судах, правозащитных и гуманитарных организациях. Это порождает в обществе чувство незащищенности перед будущим, ощущение бессилия, причина которого - признак не слабости общества, а «недееспособности» социальных институтов, утративших реальные возможности регулирования общественных отношений, словами Э. Гидденса - «институтов-пустышек» [5, с. 35, 36], имитирующих управление обществом.

Вызывает беспокойство, что сегодня государственная власть как все еще эффективный инструмент насилия и принуждения часто узурпируется и используется отдельными группами, кланами, промышленными корпорациями в корыстных, националистических или преступных целях. Возникают феномены «корпорации-государства», государств-изгоев, криминальных и даже террористических государств. Процесс деградации власти и образования «мафиозного государства» детально описан на историческом примере Венгрии политиком-публицистом М. Балинтом в его известной работе «Анатомия посткоммунистического мафиозного государства. На примере Венгрии». Он описывает механизм «захвата» государства «криминальным подпольем», включившимся в политический процесс [6].

Хотя, можно предположить, правильно говорить в данном случае не о «криминальных государствах», а о криминальных политических режимах, жертвами которых становятся «несостоятельные», «неразвитые» общества и государства с неразвитыми или пораженными общественными институтами, не способные на защиту своих прав и законных интересов от внутренней гибридной агрессии. Развитие термина «несостоятельное государство» (Failed State), озвученного в Стратегии национальной безопасности США за 2006 г., было предложено У. Шнеккенером (научным сотрудником в исследовательской группе «Глобальные вопросы» фонда «Наука и политика», Берлин) в статье «Распад государства как глобальная угроза. Неустойчивые государства и транснациональный терроризм» [7]. Он предложил подразделять «проблемные» государства на «слабые», «непрочные», «деградирующие или не справляющиеся со своими функциями», «несостоявшиеся или развалившиеся». Данной классификацией в настоящее время пользуется в ежегодных рейтингах несостоятельности государств международная организация World Peace Foundation, США.

Такие «захватившие государства» режимы (группы, кланы, секты, партии) способствуют национальному изоляционизму, угнетают население своих стран, провоцируют международные военные конфликты, угрожают миру и безопасности на планете, особенно с учетом разрушительного потенциала современных вооружений и угрозы распространения оружия массового поражения. Это требует выработки международных механизмов «оздоровления» подобных «захваченных» государств, критериев лишения их международно-правового статуса, юридических механизмов фиксации их компрометации.

Ученые-правоведы справедливо ставят вопрос об уголовной ответственности государств за преступные деяния [8, с. 182-192]. Достаточно вспомнить, что тягчайшие преступления против человечества и человечности в XX в. были совершены именно государствами, власть в которых была присвоена антисоциальными элементами. Ярчайшим примером злоупотребления возможностями государственного насилия в интересах конкретной группы людей стала нацистская Германия с ее доктринами «национального превосходства» и «расширения жизненного пространства», ввергшая народы мира в кровопролитнейший в истории человечества военный конфликт. Данное государство было всего в одном шаге от обладания ракетно-ядерным оружием. Трудно представить, чем это грозило человечеству. Военно-технический и научный потенциал современных государств настолько высок, что сама мысль о «военном соревновании» народов, как это было раньше, недопустима. При этом защита государств от узурпации осталась на прежнем уровне или даже ослабла на фоне широкого применения демократических процедур и развития возможностей массовой пропаганды в условиях открытого информационного пространства. 
Отрадно отметить, что уровень агрессии общества последовательно снижается. На смену вооруженным поединкам приходят методы экономической, информационной, гибридной, пропагандистской войны. Возможно, это следствие демаскулинизации патриархальной политики за счет усиления роли женщин и гендерной революции. Soft Power вытесняет собой Hard Power [9, c. 167], но угроза глобального конфликта реальна и обоснованна.

Однако в современной правовой науке и политике присутствуют призывы к созданию «сильного государства», якобы способного противостоять любым вызовам современности. Например, А.Д. Керимов признаками такого государства называет сильный властный, экономический и производственный потенциал, собственность на средства производства, монополию на насилие и принуждение, значительный государственно-бюрократический аппарат с широкими властными и регуляторными полномочиями во всех сферах общественной жизни, способность к мобилизации общества, монопольную идеологию [10].

В свете сказанного именно такое государство является наиболее привлекательной целью для «захвата» заинтересованными группами, а будучи «захваченным», представляет наибольшую внутреннюю и внешнюю угрозу. В целях противостояния вызовам современности правильнее говорить о стабильном государстве, демократические и социальные институты и основы которого надежно защищены от коррупции и узурпаций. Однако проблема стабильности государств неотделима от стабильности его оснований: нации, территории и культурного пространства, которые с неизбежностью размываются процессами глобализации.

Криминализация политических режимов, как правило, влечет глубокие поражения государственных институтов, прежде всего правоохранительной и судебной системы, призванных противодействовать преступности. В этом случае передача такими государствами функций правосудия и борьбы с преступностью наднациональным международным институтам является эффрективным средством внешнего «исцеления».

Наряду с «захватчиками» ярыми поборниками феетишизации роли государства выступают бюрократические кланы и содружества «силовых» органов, преследующих корыстные интересы сохранения властных сверхполномочий для защиты своего экономического и политического влияния в обществе. Эти оторванные от интересов социума профессиональные сообщества зачастую шантажируют общество мнимыми или искусственно создаваемыми ими же угрозами и «ритуализируют» фуннкции государства. Интересно, что даже их не обходят процессы глобализации, формируя из них организованные международные «тайные интернационалы спецслужб», как назвал их А.С. Панарин в работе «Искушение глобализмом» [11, с. 54]. Действуя в тени, они часто объединяют интересы с международными хищническими финансовыми кланами и преступными сообществами, направляя усилия на противодействие международному объединению здоровых сил общества, исповедуя принцип «Разделяй и властвуй!». Таким образом, национальным интересам различных стран угрожает не процесс глобализации, а глобализованный преступный интернационал.

Развитие информационного обмена, социальных сетей сегодня создает эфффективный механизм защиты от подобных явлений - народную дипломатию, открытый диалог и обмен информацией между простыми людьми из разных концов мира. Свобода такого взаимодействия должна гарантироваться и защищаться международным сообществом от нападок и ограничений «ревнителей» и «жрецов» государств в любой точке мира.

Противники глобализации высказывают опасение относительно «захвата» экономик вышедшими из-под государственного контроля международными фринансовыми кланами, сторонниками бесчеловечной монетаристской идеологии, нацеленными на несправедливый передел мировых ресурсов, урезание социальных функций государств. Спасение они видят в укреплении роли государства в экономике. Однако, как показывает практика, адепты монетарной политики закрепились в правительствах современных государств, успешно используя принципы монетаризма для проведения агрессивной государственной политики на глобальных фринансовых и экономических рынках. Такое явление усиливает финансовое и экономическое неравенство народов, создает условия для экономической экспансии отдельных государств, по словам Э. Гидденса, превращая всемирное братство во «всемирное пиратство» [12, с. 32].

Как справедливо писал по этому поводу российский мыслитель А.С. Панарин, «если глобализацию узурпируют известные политические силы, то выход может быть не в том, чтобы противостоять глобализации и оспаривать ее как принцип, а в том, чтобы расширить свое участие в этом процессе, попутно исправляя его перекосы. Иными словами, в отношении глобализации нельзя занимать позиции луддитов - разрушителей машин» [13, с. 397-398]. В этом случае передача международным институтам функций экономического и финансового регулирования позволит создать глобальные механизмы защиты товарных и финансовых рынков от экономических экспансий, обеспечить гарантии прав и интересов всех их участников. 
Известным аргументом «государственников» против глобализации является угроза утраты народами национального суверенитета как неотъемлемого и естественного права. Рассматривать данную проблему следует с учетом произошедшего «транзита» суверенитета и утраты духовных основ власти в Европе на протяжении XVII-XX вB. Первоначальным источником суверенитета большинства европейских государств была римская католическая церковь в лице ее главы Римского Папы, который наделял полновластием над народами по праву «наместника Сына Бога, Иисуса Христа» (Vicarius Filii Dei, Vicarius Christi) средневековых правителей - «суверенов». Как нельзя лучше данный принцип отражен в славянском термине «господарь», означающем «дарованный Господом». Таким образом, первоначально доктрина суверенитета, описанная Ж. Боденом, базировалась на трансформации божественной власти над народами в священную власть монархов - ее носителей. После буржуазных революций и падения монархий возобладала концепция «народного суверенитета», предложенная Ж.-Ж. Руссо, которая заключается в верховенстве народа в государстве, а народ рассматривается как единственный законный и правомерный носитель верховной власти и источник государственного суверенитета. Эта норма сегодня закреплена в конституциях большинства современных государств [14, с. 23-24]. Теперь источником суверенитета стал не Господь Бог, а народ - как совокупность граждан государства, а его носителем не «помазанник Божий» - монарх, а представительные и законодательные органы государства согласно принципам представительной демократии. Следствием такого «транзита» суверенитета послужили десакрализация власти в глазах общества, утрата носителями суверенитета духовной миссии (ответственности перед Богом), присвоение суверенитета правящими политическими силами (парламентским большинством), все более зависимыми от международных групп экономического и политического влияния.

Следовательно, частичная утрата суверенитета государствами в пользу международных групп влияния стала состоявшейся реальностью. В этих условиях предлагаемое глобализацией легальное делегирование части суверенитета законным и признанным международным структурам только упорядочит данный процесс.

Никакие негативные явления не способны изменить общего вектора развития социума. Рассуждения об особом пути отдельных народов столь же результативны, как попытки веером отогнать ураган. Глобализация - объективный процесс человеческой истории, знаменующий постепенное слияние семей в племена, племен - в народы, народов - в нации и цивилизации, с неизбежной утратой самобытных традиций, верований, языков и культур. Вопрос не в том, будет ли глобализация, а в том, какие и кому она принесет плоды.

Само понятие «глобализация» справедливо рассматривать не как отдельное явление, а как осознание обществом естественного процесса диалектического развития человечества в его исторической перспективе. Отрицание данного фракта - сознательное искажение сути истории, отрицание собственно прогресса. Не может быть сторонников или противников глобализации, может быть эфффективный либо неэффрективный ответ на изменяемые ею условия жизни общества.

Идеи экономической и политической конкуренции между народами базируются на устаревшей социал-дарвинистской теории выживания сильных в условиях ограниченности ресурсов и жизненного пространства для развития народов, теории «золотого миллиарда». Такие подходы более свойственны животному миру, не обладающему разумом и технологиями, не способному к познанию мира, поиску новых ресурсов и освоению новых пространств. Отсюда происходит неверная идея о необходимости агрессивной и оборонительной политики, реализуемой средствами государства. Это величайшее заблуждение прежних веков, апогеем которого стала идеология фрашизма. Опыт и современная наука говорят об обратном. Человек, обладающий разумом, способен к поиску и освоению новых энергий и ресурсов, которыми мы окружены: энергии Солнца, ветра, приливов, земного ядра, распада элементов, вплоть до сооружения сферы Дайсона, добыче ресурсов в Мировом океане, на иных планетах и астероидах.

Вопреки заблуждениям, невольным или корыстным, Создатель, повелевший людям «плодиться и размножаться», не обрек нас в замкнутом пространстве с исчерпаемыми жизненными ресурсами на неминуемую гибель и съедение друг другом. Он наделил нас Разумом - способностями к освоению не только еще больших пространств нашей планеты, но и планет Солнечной системы, дальнего космоса, которые по мере развития самого человечества возрастают экспоненциально. Таким образом, жизненным пространством и источником ресурсов для разумного человечества является вся Вселенная, в современном понимании - практически безграничная.

С осознанием этого факта происходит последовательная смена парадигмы развития человеческого общества: от множества - к единству, от конкуренции народов - к объединению. Выход на новый технологический уровень развития позволит в ближайшем будущем достичь избыточности ресурсов, забыть о борьбе за выживание, создать комфортные условия для жизни каждого 
человека за счет введения безусловного основного дохода и передачи роботам тяжелого и рутинного труда, достижения медицины значительно увеличат продолжительность жизни, технологии расширят возможности человеческого организма.

Уже сегодня перед человечеством возникают новые глобальные задачи и проблемы, решение которых невозможно силами отдельных государств. Это освоение соседних планет, к которому мы подошли вплотную, защита климата Земли, защита от ядерной войны, суперинфекций и астероидной угрозы (которые признаны наукой самыми опасными для человечества угрозами), борьба со всемирными террористическими и преступными организациями.

В новом глобальном мире все становится глобальным: мировая финансовая система, мировая торговля, наука, культура, всемирное здравоохранение, планетарный климат и даже организованная преступность. Для решения глобальных задач нужен глобальный инструментарий. Отдельные государства как институт прошлого не способны решить данные задачи самостоятельно. «Глобализация средств сообщения и коммуникаций, экономического производства и его фринансирования, продажи технологий и оружия, а прежде всего - экологической и военной опасности, ставит перед нами проблемы, которые уже не могут быть разрешены в национально-государственных рамках или общепринятым доныне способом заключения соглашений между суверенными государствами. Все говорит о том, что ослабление национально-государственного суверенитета будет продолжаться и потребует создания и расширения возможностей политического действия на наднациональном уровне», - говорит немецкий философ Ю. Хабермас в работе «Вовлечение другого» [15, с. 111].

Время требует от гражданского общества по мере развития последовательного расширения сферы полномочий местного, территориального общественного и иного самоуправления в вопросах, которые не всегда заметны для государственной власти, но могут быть эффективно реализованы на локальном уровне. Единственным решением может стать расширение практики передачи таких государственных полномочий на локальный или общественный уровень социального самоуправления, реализация их при непосредственной связи с населением с использованием информационно-коммуникационных технологий. В книге «Ускользающий мир: как глобализация меняет нашу жизнь» Э. Гидденс удачно описывает данную проблему словами американского социолога Д. Белла: «масштаб государства становится не только слишком мал для решения крупных проблем, но и слишком велик для решения малых» [16, с. 30].

Организация сложных межгосударственных отношений по каждой из международных задач потребует невероятно много сил и времени, существенно усложнит процедуру принятия решений.

Объединение усилий человечества в фрормате объединенных наций не показало себя эфрфективным механизмом решения международных задач, став полем для международной «анархической властной конкуренции между государствами» [17, с. 112]. Такой союз правильнее было бы называть не форматом «объединенных наций (United Nations)», а формой «объединенных государств (United States), к сожалению, термин уже занят)», в рамках которого происходит соревнование заведомо неравных участников, процветают конфронтации и «блоковое» мышление. Конкуренция ведущих экономических держав современности за право быть центром глобализации все больше напоминает игру без правил, когда грубо попираются принципы и нормы не только международного права, но и человечности, повышается уровень политической и военной агрессии. Благодаря этому человечество принесло слишком много необоснованных жертв на алтарь честолюбия политиков, загнавших прогресс в прокрустово ложе международных внешнеполитических конфликтов. Миру требуется «постнациональное понимание политического целого», создание нового «постполитического мира» [18, с. 112]. Необходимо подлинное объединение наций (Union of Nations) в фрормате объединения личностей (United People).

Глобализация, в 1990 г. первоначально определенная лордом Э. Гидденсом как «уплотнение сети всемирных связей, которое имеет своим следствием взаимовлияние местных и отдаленных событий» [19, р. 64], а в 2017 г. в его совместной работе с Ф. Саттоном описанная как «разнообразные процессы, через которые географически разобщенные популяции людей обретают более близкие и непосредственные связи друг с другом, становясь единым сообществом или глобальным обществом» [20, с. 14], дает уникальный шанс формирования единого наднационального социокультурного этноса - человечества, способного ко вхождению в новый «постполитический» мир. По мнению данных исследователей, можно говорить о формировании в связанном мире «глобальной взаимозависимости», когда «решения, принятые в одной точке земного шара, могут оказать огромное влияние на весь мир, а национальное государство, будучи до этого центральным актором, ныне частично утратило свою власть и способность к контролю» [21, с. 16]. Современная наука, опираясь на воззрения М. Уотерса, изложенные в работе «Глобали- 
зация» 2001 г. [22], называет три основных направления, или «измерения», глобализации: экономическое, культурное и политическое [23, с. 15]. Если первые два не вызывают сомнений, то категория политического измерения глобализации, трактуемая авторами как «растущая международная политическая кооперация (заявляющая о себе активно используемым понятием "международное сообщество" или применением многонациональных войск по поддержанию мира), которая демонстрирует политическую и военную координацию поверх национальных границ» [24, с. 15-16], может рассматриваться только как один из вариантов глобализации в сфере управления обществом.

Главной глобальной задачей должно стать именно поступательное, стабильное и безопасное развитие человеческого общества через полноценную реализацию прав и свобод каждой человеческой личности, раскрытие и развитие ее творческого потенциала в труде, науке, искусстве и духовной сорере.

Интуитивно человечество постепенно объединяет усилия, формируя систему глобальной безопасности и глобального развития, которые должны поглотить часть государственных полномочий, «впитать» суверенитет государств в отдельных отраслях. Это приведет к неизбежному «концу международной политики» и формированию мировых органов безопасности, правосудия и развития. Остальные полномочия государств могут быть постепенно переданы на местный уровень, местному самоуправлению, позволяя жителям агломераций, общин полностью и свободно регулировать вопросы жизни и совершенствования своих территорий.

Такая конструкция «расслоения государства» создаст посылы и гарантии глобальной безопасности и развития человечества, сконцентрировав в руках местных общин большую часть вопросов их повседневной жизни. При этом муниципалитеты из государственно-территориальных единиц преобразуются в корпорации жителей, участников хозяйственных и финансовых отношений. Подобный подход к муниципалитетам уже широко применяется в законодательстве США, ЕС и России.

Опорой на местные, общинные интересы можно объяснить высокую эффективность правительств в небольших государствах Европы, которые, по сути, являются формой национального самоуправления народов, активно делегирующих часть суверенитета на наднациональный уровень.

Следуя этой логике, можно выделить два типа глобализации в сфере управления обществом: глобализацию наций и «народную» глобализацию. Первый тип характеризуется объединением национальных государств в глобальные международные объединения, скрепляемые международным правом. Именно этот тип можно справедливо назвать союзом неравных, где более крупные игроки «цивилизованного мира» зачастую решают задачи за счет более слабых партнеров, навязывая им свою политическую и экономическую волю. Все обозначенные опасения, связанные с процессами глобализации, всецело относятся к указанному типу. Более того, волей политиков, движущих данные процессы, такая глобализация зачастую вырождается в средство экспансии отдельных ее участников.

В последние десятилетия, благодаря развитию информационно-коммуникационных технологий, формируемому ими единому социокультурному пространству, можно говорить об ином типе глобализации в сфере управления обществом - «народной», массовом стремлении людей мира к снятию барьеров для культурного и экономического взаимодействия. Оно выражается в значительном общественном давлении на власти национальных государств, в основном молодежи, по вопросу участия таких государств в процессах глобализации, передаче части полномочий наднациональным структурам. Такой народный порыв объясняется очевидным осознанием гражданами преимуществ снятия барьеров для экономического и социального развития. По данному пути идут общества стран Восточной Европы, требующие от политиков ускоренной евроинтеграции. При этом интересы политиков - представителей как стран - кандидатов, так и стран участниц глобальных образований не всегда совпадают со стремлением социума, что приводит к реальным политическим конфликтам.

Ученые высказывают обоснованные предположения, что в ближайшем будущем «можно ожидать организацию социальных движений, превосходящих уровень местной или национальный политики» без участия существующих международных организаций [25, с. 17-18]. Это позволяет говорить о феномене пробуждения массового глобального самосознания на фоне неспособности политиков и создаваемых ими международных организаций решать жизненно важные для человечества вопросы в таких сферах, как экология, здравоохранение, защита прав и свобод человека, социальное обеспечение.

В связи с этим остро требуются международно-правовые механизмы защиты интересов общества в реализации естественного права на участие в глобализации, учитывающие законные права и интересы всех участников данного процесса. Глобализация должна быть открытым и 
честным процессом, а не достоянием «избранных народов». Необходимо не только расширять европейский проект, но и активно использовать его опыт для глобализации иных регионов.

Трансформация государственных образований, конечно, будет носить постепенный, эволюционный характер в виде образования глобального союза (или нескольких), затягивающего в свою орбиту все больше народов и территорий. Временным исключением могут стать «захваченные» государства, угрожающие миру и безопасности, народы которых не способны к самостоятельному освобождению и выбору своей судьбы, чья перспектива должна определяться мировым сообществом исключительно на основе норм международного права и уважения естественных прав личности, народов и государств.

Обращение к международному взаимодействию в кризисных ситуациях - лучший критерий дееспособности государства. Иначе оно становится слабым звеном цепочки глобального развития.

Огромная роль в этом процессе будет принадлежать всемирному праву, мировой законности, на долю которой выпадет сложение каркаса новых глобальных отношений, обязанного быть прочным и обеспечивать мир и справедливость новой эры человечества. Идеи всемирного права (ius gentium) и всемирного гражданства (ius cosmopoliticum) были объявлены естественным продолжением государственного и международного права для достижения вечного мира еще И. Кантом в работе «К вечному миру» [26].

Миссия всемирного права - законодательное урегулирование глобализованных процессов, в силу объективных обстоятельств вышедших из сферы национального государственного регулирования, заполнение данного правового вакуума на основе норм, принимаемых всеми, в перспективе каждого. Способами формирования такого права в современных условиях могут стать:

- признание приоритета норм международного и транснационального права над нормами национального законодательства;

- принятие национальными легислатурами типовых (модельных) актов и кодексов;

- формирование глобальных законодательных органов с делегированием им полномочий отдельными государствами.

Особая роль также принадлежит созданию всеобщей духовности, взаимослиянию судеб, личностей и народов в единый общечеловеческий «сплав», планетарную и космическую Ноосферу, развитие которой предсказывал русский ученый В.И. Вернадский на заре XX в. [27].

Можно ли говорить о перспективе формирования в ближайшем будущем некоего глобального «супергосударства» в планетарных масштабах, о чем размышлял в упомянутой работе Л. Кор [28]. По нашему мнению, на данном этапе это преждевременно. Новый глобальный информационный миропорядок не предполагает централизацию властных полномочий в какомлибо географическом центре, он обязан быть многополярен, правильнее сказать, распределен. В противном случае принцип взаимослияния подменится принципом поглощения, возможно, породив трагедию порабощения народов планетарного масштаба, по словам И. Канта, это привело бы к «самому ужасному деспотизму» [29, с. 103].

Эволюционное угасание роли государства в XXI в. не будет скоротечным. Возможно, утратив реальные функции, государства еще надолго переживут сами себя, сохраняясь, подобно монархиям, номинально в силу традиции. Однако хочется верить, что в будущем человечество переживет новый золотой век духовного, культурного, экономического подъема и единства, а опыт сильной и централизованной государственности может потребоваться объединенному глобальному человечеству лишь при возможном взаимодействии с иными внешними недружественными силами, цивилизациями.

\section{Ссылки:}

1. Матюшкин Н.И. В.И. Ленин о дружбе народов. М., 1954. 40 с.

2. Кор Л. Распад государств / пер. с англ. К.А. Фурсова. М., 2007. 262 с.

3. Уикхем К. Средневековая Европа: от падения Рима до Реформации : пер. с англ. М., 1990. 536 с.

4. Глобализация ускорит распад государств [Электронный ресурс] : интервью : пер. с англ. // Росбалт : информационное агентство. 2005. 27 мая. URL: http://www.rosbalt.ru/main/2005/05/27/210531.html (дата обращения: 24.06.2020)

5. Гидденс Э. Ускользающий мир: как глобализация меняет нашу жизнь / пер. с англ. М.Л. Коробочкина М., 2004. 120 с.

6. Балинт М. Анатомия посткоммунистического мафиозного государства. На примере Венгрии : пер. с венгерского. М., 2016. 392 c.

7. Шнеккенер У. Распад государства как глобальная угроза. Неустойчивые государства и транснациональный терроризм // Internationale Politik. 2003. № 6. С. 17-28.

8. Современное государство в эпоху глобальных трансформаций : аналитический доклад / И.М. Рагимов, С.Н. Бабурин, Ю.В. Голик, Ю.И. Дук, А.И. Коробеев. М., 2019. 342 с.

9. Хабермас Ю. Вовлечение другого. Очерки политической теории : пер. с нем. СПб., 2001. 417 с.

10. Керимов А.Д. Некоторые проблемы теории сильного государства // Социодинамика. 2013. № 3. С. 1-45. https://doi.org/10.7256/2306-0158.2013.3.560.

11. Панарин А.С. Искушение глобализмом. М., 2003. 384 с.

12. Гидденс Э. Указ. соч. С. 32. 
13. Панарин А.С. Указ. соч. С. 397-398.

14. Черниченко С.В. Государство как личность, субъект международного права и носитель суверенитета // Российский ежегодник международного права. 1993-1994. СПб., 1995. С. 13-44.

15. Хабермас Ю. Указ. соч. С. 111.

16. Гидденс Э. Указ. соч. С. 30.

17. Современное государство ... С. 112

18. Там же.

19. Giddens A. The Consequences of Modernity. Cambridge, 1990. 186 p.

20. Гидденс Э., Саттон Ф. Основные понятия в социологии / пер. с англ. Е. Рождественской, С. Гавриленко. М., 2018. 336 с.

21. Там же. С. 16.

22. Waters M. Globalization. L., 2001. 268 p.

23. Гидденс Э., Саттон Ф. Указ. соч. С. 15.

24. Там же. С. 15-16.

25. Там же. С. 17-18.

26. Кант И. К вечному миру // Сочинения. В 6 т. М., 1963-1966 Т. 6. С. 257-311.

27. Яншина Ф.Т. Ноосфера: утопия или реальная перспектива // Общественные науки и современность. 1993. № 1. C. $163-173$

28. Кор Л. Указ. соч.

29. Кант И. О поговорке «Может быть, это и верно в теории, но не годится для практики» // Там же. Т. 4, ч. 2. С. 59-106.

Редактор: Тюлюкова Мария Олеговна Переводчик: Кочетова Дарья Андреевна 